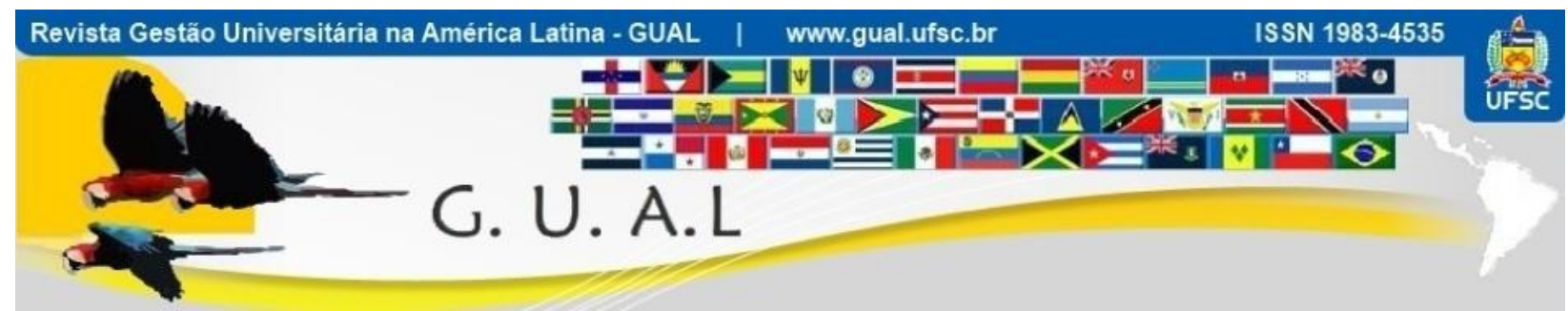

\title{
A RACIONALIDADE PEDAGÓGICA SUBJACENTE: 0 QUE ESTÁ POR TRÁS DOS DISCURSOS DOS PROFESSORES DO CURSO DE CIÊNCIAS CONTÁBEIS?
}

\section{THE RATIONALITY UNDERLYING PEDAGOGICAL: WHAT IS BEHIND THE SPEECHES OF PROFESSORS OF ACCOUNTING SCIENCES?}

Ruth Carvalho de Santana Pinho, Doutora Universidade Federal do Ceará - UFC rcspinho@ufc.br

Jacques Therrien, Doutor Universidade Federal do Ceará - UFC e Universidade Estadual do Ceará - UECE jacques@ufc.br

Recebido em 02/setembro/2014

Aprovado em 22/junho/2016

Sistema de Avaliação: Double Blind Review

Esta obra está sob uma Licença Creative Commons Atribuição-Uso. 


\title{
RESUMO
}

$\mathrm{O}$ enfrentamento dos dilemas educacionais requer uma racionalidade diferente daquela oriunda do pensamento dominante. Entendendo-se a racionalidade pedagógica como elemento fundante da ação educativa, tornou-se pertinente investigar como esta integra o projeto político-pedagógico, o currículo e as práticas docentes em um curso de nível superior. Assim, o objetivo geral deste trabalho é analisar os aspectos que evidenciam e caracterizam a racionalidade pedagógica do corpo docente do Curso de Ciências Contábeis da UFC. Em face da natureza dos elementos a serem analisados e em função do problema de pesquisa, optou-se pela modalidade de pesquisa colaborativa, utilizando-se de técnicas tais como as entrevistas com grupos focais e as sessões reflexivas. Conclui-se que aspectos da racionalidade pedagógica que podem ser sintetizados na capacidade de justificar as suas práticas, no equilíbrio das diversas racionalidades que se fazem presentes e imprescindíveis na formação do aluno de Contabilidade, o qual permite inclusive, a elaboração de concepções próprias sobre a prática docente, propiciará por intermédio do projeto político-pedagógico, do currículo e das práticas docentes uma ação educativa reflexiva e transformadora.

Palavras-chave: Racionalidade pedagógica. Projeto político-pedagógico. Trabalho docente.

\begin{abstract}
The face of educational dilemmas requires a different rationality different from those the dominant ideology. Understanding the pedagogical rationality as a established element of educational action, became relevant investigate how this integrates the political pedagogical project, the curriculum and the faculty practices in higher education. Thus, the main purpose of this work is to analyze the aspects that reveal and characterize the rationality faculty members practices in the Undergraduate Accounting Program of the Federal University of Ceará-UFC. In view of the nature of the elements to be analyzed and on the basis of the research problem, it was opted to the modality of collaborative research, using research techniques such as focal group interviews and reflexive sessions. It was concluded that aspects of pedagogical rationality that can be synthesized in the ability to justify their practices, the balance of the various rationalities that are present and are essential in the formation of the accounting student, which allows even the drafting of own concepts about faculty practices, will provide through the political pedagogical project, the curriculum and faculty practices an action reflexive educational and transformative.
\end{abstract}

Keywords: Pedagogical rationality. Political pedagogical project. Teaching work. 


\section{INTRODUÇÃO}

A complexidade do fenômeno educacional envolve aspectos tanto técnicos quanto humanísticos, fazendo com que a dinâmica dessa dupla dimensão requeira do pesquisador atenção particulares à racionalidade que articula a abordagem do seu objeto de investigação. A análise do projeto político-pedagógico, do currículo e das práticas docentes em um curso de nível superior requer uma abordagem transdisciplinar e multirreferencial, tornando-a ao mesmo tempo, complexa e instigante. Daí, a afirmação de Sacristán (1999) de que falar em educação representa referir-se a um mundo de significados variados: promover nas pessoas, enquanto indivíduos, membros de um grupo social ou profissionais, qualidades, aspirações sociais compartilhadas e percepções, obtidas por meio de processos e atividades elaboradas com o fito de atingir esse fim.

Desta forma, o estudo acerca da racionalidade pedagógica como elemento que articula o projeto político-pedagógico, com o currículo e as práticas docentes, trará uma contribuição para o entendimento das múltiplas realidades vivenciadas no âmbito das universidades públicas, notadamente do Curso de Ciências Contábeis da Universidade Federal do Ceará. Acrescente-se o fato de o ensino superior ser, em parte, exercido por docentes sem formação pedagógica e também abranger um universo de variados campos do saber, com profissionalidades, identidades, práticas e currículos bastante diversificados; e, dado o compromisso social da universidade em não só transmitir, como também gerar conhecimento, torna-se necessário um aprofundamento do tema.

Essa ambiência consolida a clareza de que conduzir a pesquisa de outra forma que não fosse a colaborativa seria inadequado. Na medida em que o objeto é, praticamente, o fator determinante da metodologia a ser adotada, falar em racionalidade, elaboração coletiva de um projeto político-pedagógico, currículo, práticas compartilhadas, sem utilizar o diálogo e a reflexão do grupo nesta empreitada seria igualmente incoerente.

Dada a pertinência dessas inquietações, o desenvolvimento desta investigação pretendeu pesquisar os aspectos da racionalidade pedagógica presentes no currículo e nas práticas docentes do Curso de Ciências Contábeis da UFC. Na sequência, são abordados os principais aspectos considerados na realização desta investigação. 


\subsection{A PROBLEMÁTICA}

As universidades passaram a elaborar os projetos político-pedagógicos em razão da determinação legal da lei federal 9.394/96, a Lei de Diretrizes e Bases da Educação Nacional (LDB). Cada instituição ou curso enseja um PPP singular, portanto, este não deveria se ater ao formato burocrático. Trata-se de um instrumento da gestão dinâmico, pelo que deve ser elaborado, avaliado e reelaborado constantemente à medida que as concepções e necessidades mudem. Do exposto, depreende-se que uma determinação legal não é suficiente para ensejar um projeto político-pedagógico adequado e muito menos, propiciar a execução deste, assegurando os resultados esperados quanto à qualidade do ensino e à efetividade da formação.

Em cursos, tais como o de Ciências Contábeis da UFC, cuja tradição é de uma formação tecnicista, o PPP não pode ser um instrumento de retórica. O contexto no qual o profissional contador atua exige discernimento na aplicação dos conhecimentos técnicos, uma vez que lida com situações dinâmicas.

O ensino superior de Contabilidade que pretende formar um profissional crítico e um cidadão capaz de intervenções deverá integrar, simultaneamente, práticas pedagógicas aos conteúdos curriculares de formação específica, visando não apenas à melhoria na formação profissional, mas simultaneamente à melhoria nas relações estabelecidas pela condição humana. É preciso integrar estes dois elementos pela inauguração de uma diferente racionalidade, pois do contrário, as reformas curriculares estabelecerão um novo perfil para o profissional, mas as práticas continuarão a contradizê-lo.

Compreende-se que no sistema educacional como um todo, há um intenso poder regulatório que retirou das próprias unidades de ensino a autonomia para decidir o que é melhor para a instituição e o formando. Considerando-se, contudo, as especificidades que caracterizam o profissional da Contabilidade e, consequentemente, o docente nesta área e, ainda, a elaboração pela primeira vez, do projeto político-pedagógico do Curso de Ciências Contábeis da UFC, tornou-se pertinente uma análise sob a óptica do pensamento educacional, orientada pelo seguinte problema de pesquisa: Quais aspectos do projeto políticopedagógico, do currículo e das práticas docentes, revelam a racionalidade do corpo docente do Curso de Ciências Contábeis da UFC? Que racionalidade é essa?

Para responder a uma questão deste porte, tão complexa, quanto sedimentada em aspectos subjetivos, foram estabelecidos alguns pressupostos que poderão facilitar a busca da 
resposta para o problema. Observações empíricas confirmaram que há uma crença implícita de que a formação pedagógica do professore se restringe ao conhecimento do conteúdo, acrescentando-se a isto apenas a habilidade de expor tal conhecimento. Este fato talvez fosse menos nocivo se, nos cursos superiores de Ciências Contábeis, a formação recebida não estivesse tão vinculada à memorização de conteúdos de natureza legal e tributária.

A compreensão distorcida sobre a autonomia e a liberdade de cátedra fortemente presente nas universidades públicas, reforça o perfil individualista da profissão contábil, concorrendo para que processos antidemocráticos sejam concretizados e percebidos com naturalidade pelos que os fazem e, muitas vezes, com o aval daqueles que foram alijados e, ao mesmo tempo, são os potenciais interessados na discussão. Surge ainda, outra anomalia que é a dissociação entre o conteúdo dos documentos de natureza pedagógica e a prática dos professores, criando verdadeiras obras de ficção pedagógica. Em síntese, se apresentam os seguintes pressupostos:

i. O predomínio da racionalidade instrumental faz com que o trabalho pedagógico esteja centrado na execução de conteúdos prescritos nas ementas das disciplinas.

ii. A ausência de uma racionalidade comunicativamente motivada impede que o PPP ressignifique o currículo e as práticas docentes do Curso de Ciências Contábeis da UFC.

Os objetivos estabelecem a direção da pesquisa, explicitando os propósitos, a intenção e as ideias que norteiam a investigação. A discussão sobre projetos político-pedagógicos enseja a compreensão ampla dos componentes que os constituem, entendendo que antes de serem determinantes da ação pedagógica, referidos documentos são determinados pelos sujeitos que a executam. Caracterizada a problemática que cerca a formação contábil, que se ressente da ausência de uma conotação mais totalizadora do ser humano e tendo pressupostos que apontam aspectos da racionalidade que favoreceriam uma ação educativa nesses moldes, o objetivo geral desta investigação é analisar os aspectos que evidenciam e caracterizam a racionalidade pedagógica do corpo docente do Curso de Ciências Contábeis da UFC. Nesta perspectiva, os objetivos específicos foram assim delineados:

i. Conhecer o perfil e as práticas docentes do Curso de Ciências Contábeis da UFC.

ii. Identificar, por meio de reflexões, a racionalidade predominante que orienta a concepção do currículo e orienta as práticas docentes no Curso de Ciências 
Contábeis da UFC, estimulando, conforme se mostre necessário, o desenvolvimento de uma nova racionalidade.

Os objetivos encontram-se alinhados com a opção metodológica da investigação, haja vista que se coadunam com a realização de uma pesquisa colaborativa, desdobrando-o em etapas sequenciais e progressivas, de forma a captar as percepções dos sujeitos por todos os ângulos. Revelam ainda a relevância científica da investigação que se justifica pela compreensão de um espaço pedagógico como o contábil, ainda muito pouco explorado e compreendido.

\subsection{PROCEDIMENTOS METODOLÓGICOS DE INVESTIGAÇÃO}

Esta subseção descreve as etapas da investigação, consubstanciadas na pesquisa colaborativa. A pesquisa-ação ${ }^{1}$ colaborativa se diferencia de outras, sobretudo porque privilegia atitudes de colaboração e reflexão crítica, visto que os pares integram-se ao processo investigativo que se delineia pela participação ativa e anuência destes, obtida por meio de negociações coletivas.

Fiorentini (2006, p.132), sintetiza o pesquisar colaborativamente como o envolvimento de professores da escola e da universidade em projetos que enfrentam "[...] o desafio de mudar as práticas escolares e de contribuir para o desenvolvimento de seus participantes". A produção de conhecimentos, nesta perspectiva, deixa de ser privilégio de um grupo de intelectuais e elimina a bifurcação entre teoria e prática.

Entende-se que a pesquisa colaborativa representa mais que um processo de intervenção na realidade; significa uma forma de elaboração de conhecimentos compartilhada, da qual auferem ganhos, pesquisador e colaboradores. Desgagné (2007) argumenta que no plano epistemológico, a pesquisa colaborativa enseja a elaboração de conhecimentos ligados a uma dada prática profissional, devendo considerar o contexto real, observando em que os elementos contribuem para sua estruturação.

Em síntese, as pesquisas colaborativas apresentam modelos investigativos que rompem com a lógica empírico-analítica originados no uso da reflexão e da prática de colaboração como estratégias que servem para os professores compreenderem ações, desenvolverem capacidade de resolver problemas e trabalharem com mais profissionalismo.

\footnotetext{
${ }^{1}$ Tipo de pesquisa social com base empírica que é concebida e realizada em estrita associação com uma ação ou com a resolução de um problema coletivo e no qual os pesquisadores e os participantes representativos da situação ou do problema estão envolvidos de modo cooperativo ou participativo (THIOLLENT, 2005, p.16).
} 
Nestes moldes, adotou-se uma abordagem multidimensional, implementada em duas perspectivas. Na primeira perspectiva foi realizada uma pesquisa envolvendo documentos relativos ao Curso de Ciências Contábeis, incluindo Atas da Coordenação, projeto políticopedagógico, propostas curriculares, dentre outros. Esse levantamento documental visou confrontar a disposição das disciplinas, os prerrequisitos estabelecidos, os objetivos dos programas de ensino e as práticas relatadas pelos professores, além de analisar a congruência em relação ao PPP.

A segunda perspectiva foi desenvolvida em dois momentos, tendo o primeiro, o objetivo de caracterizar e formar o grupo de docentes que integraria a pesquisa, mediante aplicação de questionário e de entrevistas com grupos focais; e o segundo, a realização da pesquisa colaborativa propriamente dita. No primeiro momento foi aplicado um questionário estruturado com perguntas fechadas e abertas, direcionado a todos os professores efetivos do Curso de Ciências Contábeis da UFC, visando a identificar as características pessoais e profissionais do grupo e assim obter subsídios para levantar suas identidades e práticas como docentes. Deste, participaram vinte e cinco professores. As entrevistas com os grupos focais cujo fito era selecionar os professores com perfil para participar da pesquisa colaborativa propriamente dita, contaram com vinte e um professores. Posteriormente, das reflexões desenvolvidas participaram onze professores. Ambas requereram a preparação de roteiros de perguntas, aos quais eram adicionadas questões formuladas de acordo com a necessidade de compreensão ou interesse da pesquisa.

\section{RACIONALIDADE}

Sendo o homem um ser racional, este dispõe de uma capacidade, que é subjetiva, de pensar. Por intermédio desta, discerne, analisa, compara, conclui, dentre outras atividades cognitivas decorrentes do uso da razão. Razão, portanto é a capacidade de pensar e organizar

esse pensamento. À forma como este pensamento se estrutura e o agir sistemático proveniente desta, denominou-se racionalidade. A racionalidade é a objetivação da razão, referindo ao "modo como cada sujeito articula seus saberes para compreender um fenômeno do mundo, da vida, ou ainda para justificar o seu modo de agir" (THERRIEN, 2012,p.117). Num determinado contexto de evolução humana e social, esta alcançou níveis relevantes de subjetivação que tornaram o pensamento científico um mero instrumento, surgindo ai a racionalidade instrumental ou técnica. 
A Teoria Crítica $^{2}$ se contrapõe ao predomínio dessa racionalidade e tem em Habermas um dos seus maiores representantes. A princípio, é preciso ressaltar que para Habermas (2003), racional é a pessoa que interpreta suas necessidades à luz dos padrões culturais apreendidos e que se expressa com argumentos fundamentados ante um interlocutor qualquer buscando o convencimento, ressaltando as implicações e consequências éticas e práticas destes e agindo em conformidade. Racionalidade, por sua vez, é a disposição de sujeitos capazes de linguagem e ação. Para a Teoria da Ação Comunicativa, formulada em Habermas (1967), a fala é um processo de entendimento entre sujeitos (intersubjetivo) sobre determinados objetos. Não se trata de negar a razão, mas reavê-la numa concepção ampliada da tradicional, ressaltando a relação dialética entre a ação instrumental e a ação comunicativa.

Considerando que a racionalidade está presente em todos os atos humanos, o fazer pedagógico por sua vez, tem uma racionalidade própria. O saber docente requer, por conseguinte, uma racionalidade específica, dialógica e emancipadora. A racionalidade pedagógica se coloca como a possibilidade de enfrentamento dos dilemas educacionais, pelos quais o professor se vê atrelado às engrenagens de um sistema dominado pela racionalidade instrumental, mas percebe que esta não traz respostas para os componentes indeterminados e imprevisíveis, inerentes ao trabalho docente.

Therrien (2006) postula a ideia de que a intervenção pedagógica é moldada por uma racionalidade que lhe confere especificidade fundante, permeada pela racionalidade dominante no mundo contemporâneo e pela caracterização do trabalho docente, e são estes elementos que permitem melhor compreensão da racionalidade que dá suporte à práxis pedagógica. Para Therrien e Souza (2000, p.2), “compreender a racionalidade do fazer pedagógico significa desvelar as "certezas" que dão suporte às decisões do professor, explorar o universo epistemológico que fundamenta o seu agir". Trata-se, portanto de uma racionalidade eminentemente prática. Prática no sentido que articula os diversos saberes do professor desde os curriculares até os experienciais.

Para melhor compreensão da racionalidade docente, é preciso situá-la nos contextos onde se encontra. Elementos que caracterizam o trabalho docente e a diversidade de saberes que o professor tem que articular para consecução dos objetivos educacionais fazem com que este tenha que lidar dialeticamente com a racionalidade objetiva e subjetiva. A necessidade de

\footnotetext{
2 é uma abordagem teórica que, contrapondo-se à teoria tradicional, de tipo cartesiano, busca unir teoria e prática, ou seja, incorporar ao pensamento tradicional dos filósofos uma tensão com o presente.
} 
mediar a pluralidade de racionalidades, entendendo que todas são importantes na formação do sujeito, com base nos próprios saberes e no trabalho que lhe confere uma identidade profissional, são articulados por esta racionalidade pedagógica.

Para Therrien (2006, p.8), “é inconcebível uma racionalidade pedagógica fora do contexto da epistemologia da prática ${ }^{3}$ ". A práxis educativa como processo de reflexão sistemática pelo qual sujeitos voltados para a formação de conhecimentos e saberes que refletem os significados e sentidos na perspectiva da transformação do mundo por intermédio da emancipação do indivíduo e consequentemente, da sociedade, sustenta esta racionalidade.

Destaca Therrien (2006, p.8) que a racionalidade pedagógica é,

complexa, interativa, dialógica, intersubjetiva, mas que não exclui a racionalidade instrumental, procurando integrá-la ao processo de emancipação humana. [...] $\mathrm{O}$ entendimento decorrente desta complexa racionalidade pedagógica condiciona a formação de consensos que refletem interdisciplinaridade e multirreferencialidade ${ }^{4}$ como expressões científicas de verdades e sentidos, os quais estão em constante reelaboração. É este confronto de múltiplos saberes e diferentes visões que deve orientar a elaboração de projetos político-pedagógicos e novos currículos que conduzirão à formação de sujeitos emancipados.

O reconhecimento de que existe no campo educacional um embate entre dois paradigmas de racionalidade, ou seja a racionalidade instrumental e a racionalidade comunicativa), não é suficiente para empreender mudanças significativas na condição de educadores e educandos, traduzidas em melhores condições de trabalho e uma educação de qualidade. Esta articulação é propiciada no âmbito do trabalho docente que é uma atividade interativa e é constituído em parte pelos saberes, pelo que se sobressai à epistemologia da prática, nos moldes críticos, como princípio que fundamenta a transformação e o amálgama dos diversos saberes em saberes docentes, por meio de uma racionalidade própria, a pedagógica moldada na dialogicidade. Uma racionalidade que está segura quanto ao sentido da educação, que não se coaduna com o mero preparo de profissionais para atender aos interesses do mercado de trabalho, mas tem o foco na formação integral do indivíduo. Com esta fundamentação, procedeu-se à análise do Curso de Ciências Contábeis da UFC, objeto da seção seguinte.

\footnotetext{
${ }^{3}$ Fundamentos da formação do saber com base na ação e reflexão crítica. Nesta concepção o conhecimento procede da reflexividade, mas uma reflexividade crítica que contempla o conhecimento e a experiência vivida na realidade.

${ }^{4}$ Composição com instrumentos teóricos de outros e de vários campos de saber. Envolve uma compreensão mais abrangente (quebra da monorracionalidade), do fazer ciência ou fazer formação de professores ou pesquisadores.
} 


\section{EM BUSCA DA RACIONALIDADE DOCENTE DO CURSO DE CIÊNCIAS CONTÁBEIS DA UFC}

Esta seção apresenta os resultados da pesquisa documental com análise descritiva, da aplicação de questionários para levantamento de informações sobre o corpo docente do Curso de Ciências Contábeis da UFC, das entrevistas com grupos focais e da pesquisa colaborativa.

Considerando-se que não existe uma só racionalidade nem apenas um saber na concepção do trabalho docente (THERRIEN, 2006; CUNHA, 2007), percebeu-se pelas respostas sobre planejamento das aulas, conteúdo programático e práticas mais frequentes, que alguns professores vivenciam um discreto processo de transição paradigmática, pelo qual ainda se observam, de forma predominante, nas práticas e discursos destes, aspectos referendados na razão instrumental. Podem, todavia, ser observados, também, alguns movimentos, um tanto quanto incipientes, que apontam para o surgimento de uma racionalidade própria, característica do trabalho docente que exercem no Curso.

Alterações legais e das normas contábeis, a renovação do corpo docente e até mesmo o aspecto identitário são elementos desse embate. Para que possam equilibrar a coexistência de uma racionalidade instrumental e uma comunicativa, ambas necessárias ao desenvolvimento de um curso dessa área do conhecimento é preciso a adoção de uma prática reflexiva e de um ensino dialógico que proporcione aos formandos uma educação que os emancipe da instrumentalidade dominante.

Pelo levantamento, notou-se que os aspectos que denunciam a diversidade de racionalidades se evidenciam na opção pela aula expositiva e o uso de quadro branco e pincel, além do data-show, como estratégia e recursos didáticos mais utilizados, contrapondo-se à adaptação dos conhecimentos científicos à linguagem dos alunos e o estímulo à elaboração de conceitos próprios por estes. Esta e outras contradições evidenciadas confirmam a coexistência de racionalidades diferentes, mas no pressuposto da honestidade das respostas, podem significar também incompreensão de alguns conceitos pedagógicos.

A produção científica é diversificada e desenvolvida por mais da metade do Departamento, assim como a vocação e a oportunidade de ampliar e compartilhar conhecimentos, como principais motivações para o ingresso na carreira docente, forjam o ambiente propício para formação de um novo perfil do contador.

Esta mudança de perfil concorre para que haja mudanças também no trabalho docente dos professores de Contabilidade. Em geral, este reflete o isolamento do contador no âmbito 
das empresas e esta experiência é reforçada pela própria privacidade da sala de aula e retratada pela análise dos questionários quando aponta a prática de discussões com os alunos e com os próprios colegas com os menores índices de resposta.

Assim, o destaque dado nesta análise aos aspectos que enfatizam a existência de um forte componente instrumental na prática desses professores, longe de ser uma crítica preconceituosa, significa uma preocupação em distinguir estes, dos princípios de uma racionalidade comunicativa ou intersubjetiva. Entende-se que a docência do Curso, devido à formação e experiências ocupacionais e condições institucionais, é realizada em estreitos limites e estes com certeza, fazem o melhor dentro destas condições.

O levantamento demonstrou ainda que em se tratando de identidade dos sujeitos na qualidade de docentes do Curso de Ciências Contábeis da UFC, o traço que melhor a define é a formação profissional como contador, porém não é suficiente para agregá-los, até mesmo pelas próprias condições institucionais. Consequentemente, um processo de ampliação e consolidação de mudanças não ocorre espontânea nem isoladamente, e nisto, acredita-se, esta pesquisa poderá, com a colaboração dos próprios professores, identificar a racionalidade presente no PPP, por intermédio do currículo e das práticas docentes.

Para realização das entrevistas com os grupos focais, os professores do Departamento de Contabilidade foram divididos em quatro grupos. Foram convidados para participar apenas os vinte e cinco docentes que anteriormente, responderam ao questionário, mas só atenderam ao convite, vinte e um professores. O critério para formação dos grupos foi inicialmente, a divisão entre os que tinham experiência administrativa na UFC e os que não a possuíam. $\mathrm{Na}$ sequência, cada um destes grupos foi dividido em dois, separando-se os que tinham mais de dez anos e os que tinham menos de dez anos de trabalho como docente na UFC. Objetivou-se com isso, identificar se os resultados estariam ligados ao tempo de trabalho e à experiência docente. Para subsidiar esta nova divisão, recorreu-se a Tochon (1992), o qual assevera que o desenvolvimento profissional do professor passa por fases. Como era fácil de supor, esta divisão foi, em parte, desfeita, porque alguns, por compromissos outros, pediram a mudança do dia ou horário, acarretando na impossibilidade de analisar separadamente.

Com base em Gibbs (2009), procedeu-se à análise qualitativa dos dados, iniciando-se por codificar o texto no sentido de captar os sentidos e as interpretações dos entrevistados. Procurou-se não esgotar a análise neste ponto, principalmente porque a finalidade dos grupos focais, nesta pesquisa, era a de selecionar os professores que efetivamente participariam da 
pesquisa colaborativa, classificando-os em Perfil técnico ou instrumental, Perfil práticoreflexivo e Perfil crítico-reflexivo (FENDLER, 2003; GHEDIN, 2007).

O processo de codificação do texto com uma síntese das falas, segregadas de acordo com as categorias analíticas, e a definição, por meio da análise tipológica, resultou na seleção dos professores que se aproximavam do perfil crítico-reflexivo. Naturalmente, a classificação exposta é uma aproximação da tipologia estabelecida por Fendler (2003) e Ghedin (2007) e por isso mesmo provisória e susceptível aos vieses em que se pôde incorrer na pesquisa. Tem, por conseguinte, o mérito de apenas apontar os sujeitos com maior potencial colaborativo.

Observou-se a predominância do perfil instrumental, mas já se encontram alguns professores que esboçam uma postura mais reflexiva e até mesmo crítica. Entende-se que, se no mundo do trabalho sobra pouco espaço para a crítica, na academia esta passa a ser também, a marca do próprio trabalho docente, pesando sobre eles a responsabilidade de preparar o aluno para se submeter a este universo.

Constatou-se que a concepção sobre o trabalho docente e o discernimento sobre a relação dialética entre teoria e prática, assim como da pesquisa e da extensão como princípios da formação do conhecimento, fazendo do ensino uma atividade articuladora destas e não a arte de reproduzir tal conhecimento definiam o estádio da capacidade reflexiva em que se encontra o docente. Por conseguinte, o trabalho docente deve ser visto numa dimensão realística, sem autopiedade e fora de uma visão idealizada e poética. No que diz respeito à pesquisa e à extensão, estas devem se constituir nos meios pelos quais se compreende a não hierarquização entre teoria e prática e se passa a entendê-las de forma diferente, desassociando-as, respectivamente, da aula expositiva e dos exercícios.

As respostas revelam, em algumas situações, percepções muito díspares e ressalte-se, isto não é resultado puro das diferentes identidades dos sujeitos, mas da falta de uma identidade docente que deveria ser constituída com a intermediação da própria Universidade. Destacam-se algumas exceções a esta regra, que confirmam a percepção que aflorou durante o levantamento do perfil dos docentes, qual seja, a de que algumas concepções e práticas se encontram em decurso de mudança, ou no mínimo, há uma tentativa de equilibrar as diferentes racionalidades com as quais têm que lidar.

Foram convidados para participar das sessões reflexivas os professores que se enquadraram no perfil prático-reflexivo e crítico-reflexivo. Sabe-se, contudo, que as palavras codificadas nos seus discursos apenas dão uma pista de como pensam e agem, mas 
definitivamente não os identificam. Assim, selecionaram-se aqueles que poderiam contribuir mais para a elaboração do conhecimento que ora se buscava captar e consolidar.

Por conseguinte, a este grupo, independentemente da orientação, foram adicionados os professores que ocupavam a Coordenação do Curso e a Chefia do Departamento, e, ainda, outros que não obstante apresentarem um perfil orientado pela instrumentalidade, manifestaram espontaneamente a vontade de continuar participando da pesquisa, totalizando assim onze colaboradores.

As sessões reflexivas foram desenvolvidas em quatro ações. A primeira dessas ações, denominada Descrição, nesta o docente descreveu a respectiva prática. A segunda, chamada Informação, o professor informou o que alcançou com base na prática aplicada. A terceira, a Confrontação, consistiu no momento em que a prática foi confrontada com a teoria. Por último, a quarta ação, a Reconstrução, se buscou repensar e refazer os objetivos e as práticas.

Dentre as constatações, restou claro, inclusive, que não existe uma monorracionalidade nas práticas dos professores do Curso e que intuitivamente algumas práticas destoam do ensino tradicional, havendo espaço para elaboração de uma práxis diferente.

Das sucessivas etapas, apreendeu-se, que algumas práticas docentes ensejam aprendizagens mais significativas para os alunos que não só a memorização de conteúdos e que estas convivem com outras de caráter mais instrumental. Para o uso de cada uma destas, os professores apresentam uma razão, portanto, entende-se que têm uma racionalidade específica porque sabem atribuir estas razões ao seu discurso. Percebe-se, contudo, que falta um elo que confira à racionalidade pedagógica do Curso de Ciências Contábeis da UFC um equilíbrio entre a razão instrumental e a razão comunicativa. Depreende-se que estão dissociados porque lhes falta o trabalho docente como elemento integrador, levando-a com isso a um raio de atuação que não ultrapassa a sala de aula, o que enfraquece uma análise com argumentação sólida, que a possa caracterizar, de fato, como racionalidade pedagógica genuína.

O trabalho docente no Curso precisa ser redimensionado a fim de que assuma sua característica genuína, que é a interação. Este atributo está ausente da relação professor-aluno, mas principalmente das relações do corpo docente entre si, com a Universidade e com a profissão. O processo de elaboração do PPP demonstrou isso. O não compartilhamento deste plano é causa e consequência da falta deste componente. A objetivação, subjetivação, ou 
melhor, o equilíbrio entre as racionalidades enseja um trabalho que resultará na definição do tipo de educação que se pretende para o Curso de Ciências Contábeis da UFC e sua consequente ação educativa.

Conforme já foi divisado nesta investigação, o trabalho docente e consequentemente, o agir pedagógico não se restringe à sala de aula. $\mathrm{O}$ redimensionamento do trabalho docente passa pela inauguração da epistemologia da prática como modus operandi destes professores. A constatação de que coexistem diferentes racionalidades e até mesmo uma determinada racionalidade pedagógica que não só justifica, mas também permite a alternância entre as demais, não é suficiente para garantir a ação educativa reflexiva e transformadora que se almeja. A coexistência paralela entre estas racionalidades é um fragmento da compartimentalização do mundo objetivo, social e subjetivo, que só será rompida pelo exercício sistemático da reflexão, levando ao surgimento da racionalidade pedagógica no sentido pleno, não aquele voltado para o sujeito, mas formado intersubjetivamente, por intermédio da comunicação e do consenso.

Trabalhar na perspectiva da reflexividade significa ainda considerar aspectos relacionados aos aspectos particulares do sujeito, entendendo que o professor não é uma ferramenta de trabalho e sim um ser dotado de outras dimensões, inclusive a emocional. Não se trata aqui de desvirtuar o sentido da reflexão, transformando-a em terapia de grupo, mas refletir sobre a prática docente, considerando os valores pessoais envolvidos nestas. Os saberes formulados na experiência, o deslocamento das identidades modernas, dentre outros aspectos, devem ser valorizados e trabalhados, a despeito da tendência nas universidades de valorizar apenas os conhecimentos disciplinares e os índices de produtividade acadêmica, que se ressalte, são importantes, mas não sobrepujantes.

Esta abordagem remete a questionar-se o fato de que se com este processo, a autonomia dos professores não estaria ameaçada. Entende-se que não, pois o conhecimento que gera autonomia também é construído pelo entendimento das razões dos outros, pela compreensão das suas dificuldades e pela socialização dos êxitos. Na educação e, principalmente, na educação promovida pela universidade pública, não cabe o comportamento de guardar para si os louros e de esconder os fracassos ou mesmo transferi-los para o departamento, para a faculdade, para a universidade, para o governo. Existe uma responsabilidade pública com a educação que precisa ser discutida, pois amplos interesses ideológicos e sociais estão envolvidos. Logo, autonomia não é sinônimo de trabalho isolado 
ou mesmo abertura para intervenções externas ou impróprias, mas a definição coletiva de uma ação educativa e as bases para solução dos conflitos que eventualmente surjam.

Há de se pensar que a racionalidade pedagógica é responsável pelo equilíbrio das diferentes racionalidades e não se limita a apenas intercalar uma e outra, e isto é verdade. A racionalidade pedagógica até então restrita à sala de aula, no entanto, só terá reflexos sobre o projeto político-pedagógico do Curso de Ciências Contábeis da UFC se o trabalho docente for desenvolvido de forma não mecânica, solidária e coletiva, permitindo intervenções e tendo por base a realidade do ambiente, ou seja, é preciso que a ação pedagógica seja viabilizada por um processo constituído nas bases da racionalidade comunicativa, e desta impregnada, preceda à ação educativa reflexiva e transformadora que se almeja.

\section{CONCLUSÕES}

O objetivo deste trabalho foi analisar quais os aspectos da racionalidade pedagógica dos professores do Curso de Ciências Contábeis da Universidade Federal presentes no projeto político-pedagógico, no currículo e nas práticas docentes.

A LDB e as mudanças no cenário da profíssão contábil, advindas do processo de convergência com as normas internacionais, projetam um profissional mais articulado comunicativamente, cujo cabedal técnico que já era bastante dinâmico, e é hoje ainda mais complexo, fortalecendo o debate sobre o planejamento da sua educação. Ensejou-se ainda, discutir estas questões no contexto e por aqueles que são em última instância, os responsáveis pela formação desses profissionais. Lamentavelmente, a orientação trazida por esta lei, por meio das Diretrizes Curriculares Nacionais (DCN), ao contrário do espírito de liberdade que procurou implementar, representou tão somente uma regra a ser aplicada sem a devida ponderação e adequação à realidade da instituição e da região. A compreensão acerca do que seria uma formação integral, na visão dos que trabalharam no currículo, pareceu se reduzir ao rol de conhecimentos que deveriam ser adquiridos.

A análise do projeto político-pedagógico do Curso de Ciências Contábeis não se prendeu ao teor do documento e sim aos diversos elementos que o delineiam e que fazem a transversalidade da ação educativa, restringindo-os, para fins desta pesquisa, ao currículo, às práticas docentes, ao trabalho docente e à racionalidade, tendo a racionalidade pedagógica como o fluido que circula e interliga estes elementos, por intermédio da estrutura capilar propiciada pelo trabalho docente. Acrescente-se que a racionalidade pedagógica deve ser 
trilhada no sentido de engendrar processos que permitam que o homem não permaneça escravo de uma determinada razão, mas se torne senhor dela.

Tomando por base as concepções do grupo de colaboradores, identificou-se certa perplexidade no fazer-acadêmico do corpo docente do Curso, resultante de fatores diversos. Encontram-se, de um lado, professores que receberam uma significativa influência da formação tecnicista e uma formação pedagógica inicial bastante superficial, que, diante dos próprios saberes da experiência, vêm utilizando, de forma intuitiva, métodos menos tradicionais de ensino e, do outro lado, aqueles que nas mesmas circunstâncias, por convicção, permanecem arraigados às suas metodologias tradicionais. Embora legitimem sua prática, ambos os grupos se debatem com o mesmo problema, qual seja, de convergir o método de ensino para aprendizagens exitosas. Embora consigam justificar suas práticas e fazer uso oportuno destas em sala, consoante os diferentes contextos, o que a princípio sinaliza para uma racionalidade pedagógica, na verdade, constitui-se uma variação da racionalidade técnica ou mesmo uma racionalidade pedagógica ainda não calcada na epistemologia da prática. Peca, por conseguinte, por ainda não ter alcançado a condição de, por intermédio do diálogo e colaboração com os pares, engendrar meios para produzir aprendizagem nos sujeitos. Estes meios passam, por intermédio do consenso, dar sentido aos conteúdos e não apenas transmitilos. Por sua vez, o professor também aprende e se transforma ao longo do processo.

Em suma, estes professores estão se apropriando de elementos de uma racionalidade pedagógica que, pela essência, é comunicativa, nos mesmos moldes da racionalidade instrumental. Este quadro faz com que mesmo utilizando práticas mais condizentes com a razão comunicativa, amarguem resultados similares aos que se sustentam nas tradicionais, ou no máximo consigam parecer fazer algo diferente, mas, salvo exceções, repetem as velhas fórmulas. Este comportamento, que se apresenta inconsistente, longe de ser má fé ou inabilidade dos professores, expõe a existência de um embate das racionalidades. Em meio à predominância da racionalidade técnica, aflora, sob um novo paradigma, a racionalidade pedagógica autêntica. O uso de novos meios, que representa o reconhecimento das necessidades e o anseio de mudança, sem que os princípios sejam objeto de reflexão e revisão, caracterizam essa situação, que apesar da perplexidade causada é um indicador positivo.

O forte componente técnico da profissão praticamente elimina a condição de professores como produtores de conhecimento. A legislação e os regulamentos, bem como as normas profissionais emanadas do órgão regulador da profissão, que interpretam os 
dispositivos legais e codificam condutas, fazem do profissional da Contabilidade e consequentemente do docente contador, consumidores de conhecimento e reprodutores, respectivamente. Há pouco espaço para criação em um ambiente no qual uma densa e confusa regulamentação é imposta pelo governo cujo descumprimento é sujeito a pesadas sanções. A rigor, a regulamentação não impede a crítica, mas sobra pouco tempo para isso, já que a rotina é exaustiva. Na esfera acadêmica, a pesquisa e a extensão abrem canais para essa crítica, mas se observa é que o produto destas atividades não é usado, pelo menos de forma institucional, para promover a qualidade do ensino, principalmente pelo isolamento e compartimentalização do trabalho docente.

A racionalidade pedagógica neste prisma é limitada, evidenciando-se ser capaz de dar conta apenas dos microaspectos do cotidiano da sala de aula. Como os contextos das salas de aula estão submetidos a regras adotadas espontaneamente pelos professores, ou até mesmo criadas por estes, este tipo de racionalidade propicia uma coerência com os objetivos estabelecidos por parte de cada professor, pelo que conseguem justificá-las satisfatoriamente. Quando questões de maior abrangência ocorrem, os professores se mostram despreparados para agir porque em situações de incertezas, envoltas em ambiguidades, nas quais as regras não foram formuladas ou ajustadas ao seu processo racional. $\mathrm{O}$ pensamento fragmentado, reforçado pelo alijamento da elaboração do PPP e do currículo, não lhes permite sequer encontrar as razões para entender a realidade.

No que tange ao problema desta pesquisa, alcançou-se a compreensão de que foram encontrados, muito embora não estejam sedimentados numa reconfiguração de saberes, aspectos de racionalidade que propiciam a instauração de processos educativos baseados na racionalidade comunicativa. Nesta perspectiva, elencam-se a defesa consistente de suas práticas, consoante a realidade na qual estão inseridos; a conexão com o universo profissional, por meio dos trabalhos técnicos que realizam e das constantes atualizações de conteúdos que se alia à preocupação com a transposição didática e a concepções próprias, desenvolvidas na experiência solitária da sala de aula, as quais excedem às suas restritas formações docentes. Estes aspectos identificados, no momento, são apenas potencialidades que se concretizarão quando forem trabalhados e desenvolvidos mediante uma prática reflexiva de forma sistemática, coletiva e emancipadora, sob a égide de outra racionalidade pedagógica.

Destaca-se que fato de a racionalidade pedagógica aqui vislumbrada é diferenciada, pois, na perspectiva epistemológica ao mesmo tempo em que esta estabelece o consenso e a 
solidariedade, não nega a individualidade, orientando em direção a novas configurações do saber. Permite, ainda, a retomada da valorização do trabalho docente pelo entendimento que se trata de um trabalho produtivo concebido em uma práxis ética que, consequentemente, enseja conhecimento e agrega valor.

Por fim, confirmaram-se os pressupostos do domínio da racionalidade técnicoinstrumental nas práticas docentes como responsável pelo enfoque exacerbado nos conteúdos, ressalvando-se o fato de que componentes de uma racionalidade comunicativa também foram encontrados; além da constatação de que estes componentes não foram desenvolvidos o suficiente para garantir que o PPP e o currículo efetivamente ressignificassem estas práticas. Estas constatações permitem observar o quanto é pernicioso o distanciamento dos processos educacionais daqueles que fazem a educação, desviando-a dos seus propósitos maiores de promover mudanças sociais, desnudar ideologias e reduzir as diferenças.

Assim, foram analisados os componentes que se cruzam no projeto políticopedagógico do Curso de Ciências Contábeis da UFC, permitindo levantar a tese de que é possível promover uma formação contábil menos voltada para os resultados pre-estabelecidos e mais preocupada com o atingimento dos ideais de realização humana, tendo por limites a realidade situada e histórica. A estruturação do trabalho docente do Curso por intermédio de um processo de reflexão sistemática, não pode prescindir que este processo extrapole a sala de aula e seja consequentemente coletivo, possibilitando que os professores sejam capazes de determinar o produto de seu trabalho, os fins e os meios para constituí-los. Os sujeitos mostraram-se receptivos para a pesquisa colaborativa, contrariando expectativas pessimistas quanto à viabilidade da investigação. Isto posto, o percurso metodológico pode ser analisado como congruente com os objetivos e resultados esperados. No caso em estudo, o agir comunicativo até então latente se tornou, pela pesquisa colaborativa realizado, iminente, dependendo tão só do agir estratégico advindo dos gestores acadêmicos.

Conclui-se que aspectos da racionalidade pedagógica que podem ser sintetizados na capacidade de justificar as suas práticas, no equilíbrio das diversas racionalidades que se fazem presentes e imprescindíveis na formação do aluno de Contabilidade, o qual permite inclusive, a elaboração de concepções próprias sobre a prática docente, propiciará por intermédio do projeto político-pedagógico, do currículo e das práticas docentes uma ação educativa reflexiva e transformadora. Para tanto, pleiteia-se uma nova racionalidade 
pedagógica, visto que a identificada atualmente precisa alcançar um patamar epistemológico, fundando um trabalho docente lastreado em saberes resultantes da práxis pedagógica.

Conclui-se ainda, embora seja constrangedor, que as possíveis dificuldades de realizar uma ação educativa reflexiva e transformadora não advêm exclusivamente da atual racionalidade ou de problemas relativos à formação tecnicista. Os professores demonstraram um individualismo tão intenso que beira à omissão, e para perceber isso basta o reporte ao desconhecimento do PPP, não obstante muitos terem sido representantes de órgãos colegiados ou ocupantes de posições de chefia, situação que permaneceu mesmo após seis meses da pesquisa, quando foram feitas as entrevistas de explicitação.

A revisão do PPP e do currículo deve ser a primeira etapa na trajetória do que se espera que seja uma virada no Curso de Ciências Contábeis da UFC. Esta expectativa não se prende à alteração textual dos citados documentos, mas à instauração de um processo dialogado e contínuo de discussão, pelo qual seriam reavaliados a priori, os princípios educacionais e, como consequência disto, os métodos e os conteúdos. Este processo não se esgotaria com a reelaboração dos documentos, mas instauraria um trabalho docente referendado na epistemologia da prática, fazendo desabrochar a racionalidade comunicativa, ainda latente entre os professores. Tendo o trabalho docente orientado por esta nova racionalidade pedagógica, vislumbra-se uma ação educativa reflexiva e transformadora que proporcione uma formação integral aos profissionais egressos da UFC.

\section{REFERÊNCIAS}

CUNHA, Maria Isabel da. O lugar da formação do professor universitário: a condição profissional em questão. In: CUNHA, Maria Isabel da (Org.). Reflexões e práticas em pedagogia universitária. Campinas: Papirus, 2007.

FIORENTINI, D. Produção de sabers docents a partir da reflexão, da colaboração e da pesquisa sobre a aprática. In: IBIAPINA, I. Maria L de M.; CARVALHO, Maria V.C. (Org.). A pesquisa como mediação de práticas socioeducativos. Teresin: EDUFPI, 2006, 127-143.

FENDLER, L. "Teacher Reflection in a Hall of Mirrors: historical influences and political reverberations". Educational Researcher vol. 32, n ${ }^{\circ}$. 3, pp.16-25, 2003. Disponível em: http://edr.sagepub.com/content/32/3/16.full.pdf+html Acesso em 20/09/2010.

GHEDIN, Evandro. Professor reflexivo no Brasil: da alienação da técnica à autonomia da crítica. In: PIMENTA, Selma Garrido e GHEDIN, Evandro (Orgs). Professor Reflexivo no Brasil: gênese e crítica de um conceito. 4. ed. - São Paulo: Cortez, 2006.

HABERMAS, Jurguen. Teoría de la accion comunicativa, I. 4. ed. Madrid: Taurus, 2003(a). 
Teoría de la accion comunicativa, II. 4. ed. Madrid: Taurus, 2003(b).

TARDIF, Maurice. Saberes docentes e formação profissional. 9. ed. Petrópolis: Vozes, 2008.

TARDIF, Maurice; LESSARD, Claude. O trabalho docente. 4. ed. Petrópolis: Vozes, 2008.

THERRIEN, Jacques. Os saberes da racionalidade pedagógica na sociedade contemporânea.2006(a). Disponível em www.jacquestherrien.com.br. Acesso em 01/05/2009.

Docência profissional: a prática de uma racionalidade pedagógica em tempos de emancipação de sujeitos. In: D’AVILA, C.; VEIGA, I.P.A., Org.) Didática e docência na educação superior - implicações para a formação de professores. Campinas: PAPIRUS, 2012.

THERRIEN, Jacques; SOUZA, Angela T. A racionalidade prática dos saberes da gestão pedagógica da sala de aula. 2000(b). Disponível em www.jacquestherrien.com.br. Acesso em 01/05/2009.

THERRIEN, Jacques; MAMEDE, Maíra, LOIOLA, Francisco. Trabalho docente e transformação pedagógica da matéria: alguns elementos da gestão dos conteúdos no contexto da sala de aula. 2007. Disponível em www.jacquestherrien.com.br. Acesso em 01/05/2009.

TOCHON, François V. “Trois épistémologies du bom enseignement”. Revue des sciences de l'éducation, vol. XVIII, no 2, 1992, p. 181-197. Disponível em www.erudit.org/revue/rse/1992/v18/n2/index.html .Acesso em 20/09/2010. 